\title{
Teaching and Learning during COVID 19: Perspectives of Undergraduate Oral Health Students
}

\author{
Manorika Ratnaweera*, Rohini Khareedi \\ Discipline of Oral Health, School of Clinical Sciences, Faculty of Health and Environmental Sciences \\ Auckland University of Technology \\ Auckland, New Zealand \\ ${ }^{*}$ Corresponding author's email: manorika.ratnaweera [AT] aut.ac.nz
}

\begin{abstract}
----
Introduction: COVID -19 has caused disruptions in higher education across the world. Our university adapted a blended model of learning, moving between traditional campus-based sessions and online sessions.

Material and Methods: The purpose of this study was to investigate the students' perceptions of their experience of teaching and learning during the pandemic. An anonymous electronic questionnaire-based survey was sent to students. The data was subject to analysis.

Results: 67 students responded to the survey.32.8\% of the participants felt face to face sessions were better than online sessions and $37.3 \%$ said that face to face and online sessions offer similar benefits. $37.3 \%$ preferred live online sessions while $46.3 \%$ preferred recorded videos. $40.3 \%$ of students reported finding transitioning into practical sessions challenging. $65.7 \%$ reported having been moderately impacted by COVID-19. Adaptation to online sessions, the level of engagement, the ability to seek clarifications, preparation for assessments and the ease of transition into practical sessions were all positively correlated to the level of impact by COVID-19 with $p<0.05$.
\end{abstract}

Conclusion: The adaptability to and acceptability of online teaching and learning sessions has been high. A significant number of participants have reported finding the transitioning into practical sessions challenging.

Keywords--- COVID-19, Online learning and teaching, blended learning, higher education

\section{INTRODUCTION}

COVID 19 has affected most countries albeit varyingly. New Zealand has been hailed for its success in handling the pandemic with a multitude of measures. One of the measures taken was to disrupt the chains of transmission with lockdowns. The lockdowns implemented were stringent, though relatively brief. The conventional settings of university education were disrupted during lockdowns. Educational institutions suddenly were met with a new normal. The standardized education systems in the old normal were not successfully meeting the needs of the new normal. The priority was for all those who play a role in the education to adopt a mindset of flexibility and change, identifying and supporting approaches, both old and new, that can strengthen education and training (1). Like universities elsewhere, our university moved to a blended model of learning. This model included an online teaching platform during the lockdowns, and campus-based face to face activities when lockdowns were lifted due to no evidence of community transmission.

Though online education is not new, the unprecedented outbreak has made it the predominant mode of education during lockdowns. In the second half of 2020 most Universities in New Zealand adopted the blended learning approach with part of its leaning online and a part on site. This change has been particularly challenging for courses in health sciences including dental education $(2,3,4)$ and has affected all stake holders. Health science courses were encouraged to increase in-person delivery and prioritise hands on skill-based learning, wherever safe to do so. Rapper and Brown have found that these changes in the midst of the pandemic have had significant impact on students' wellbeing (5).

The purpose of this exploratory study was to investigate the students' perceptions of their experience of teaching and learning during the pandemic. 


\section{MATERIAL AND METHODS}

This exploratory study was a questionnaire-based survey to address the following research objectives:

- To determine the impact of the pandemic on students' academic life

- To determine the acceptability of online teaching and learning methods

- To determine if online teaching and learning methods sufficiently prepared students for assessment

- To determine if online sessions were comparable to face-to-face sessions

- To determine the effectiveness of online sessions in preparing students for practical sessions (preclinical and clinical)

The questionnaire was designed with 27 questions including two open-ended questions. The questionnaire was assessed by 2 staff members for clarity. An ethics application was submitted to the University's ethics committee. The electronic survey was developed on the Qualtrics platform. Following approval, the weblink was sent to students enrolled in the first, second and third year of the Bachelor of Health Science (Oral Health) at the Auckland Institute of Technology at the end of the academic year in 2020. The survey link was accessible for 4 weeks and two e-mail reminders were sent requesting participation. The data was collected anonymously.

The raw de-identified data were entered into IBM SPSS (Statis- tical Package for Social Sciences, IBM Corporation, Endicott, NY, USA) version 26 for Windows. The variables were recoded into numerical values to render them suitable for statistical analysis. The data were subjected to descriptive and inferential statistical tests. The significance was set at 0.05 . The two open ended questions were subjected to thematic analysis and the common themes were identified.

\section{RESULTS}

Of the potential 183 participants, 67 participated in the survey, the response rate was $36.6 \%$. Of the participants, $41.8 \%$ (28) were enrolled in the first year, $40.3 \%$ (27) were enrolled in the second year and $17.9 \%$ (12) were enrolled in the third year.

35 reported being over the age of 25 and the remaining 32 reported as being 25 or under. Their ethnicities are as indicated in Table 1.26 participants reported having care-giving responsibilities during the study. 41 reported having no care-giving responsibilities. 46 participants were not in paid employment during semesters, 21 were in paid employment during semesters. Two of the 67 reported having direct exposure to COVID 19.

Table 1: Ethnicity

\begin{tabular}{l|r|r|r|r} 
& & & \multicolumn{2}{c}{$\begin{array}{c}\text { Cumulative } \\
\text { Percent }\end{array}$} \\
\hline Asian & Frequency & Percent & Valid Percent & 34.3 \\
\hline European & 23 & 34.3 & 34.3 & 58.2 \\
\hline Maori & 16 & 23.9 & 23.9 & 62.7 \\
\hline Middle Eastern/Latin & 3 & 4.5 & 4.5 & 71.6 \\
American/African & 6 & 9.0 & 9.0 & 89.6 \\
\hline Other Ethnicity & & & & 17.9 \\
\hline Pacific Peoples & 12 & 17.9 & 10.4 & 100.0 \\
\hline Total & 7 & 10.4 & 100.0 & \\
\hline
\end{tabular}

39 participants reported as being confident with technology and the remaining 28 reported as being able to manage technology. 97\% (65) participants reported to have participated in online sessions. Nearly $95 \%$ of the participants reported as having minimal problems with accessing the online sessions. Only 6\% (4) of participants felt that they were not supported by the university. $94 \%$ (63) used a laptop to access online sessions, the remaining $6 \%$ used either a mobile phone (2 participants) or a desktop (2 participants).

9\% of participants felt adapting to online sessions was difficult, $14 \%$ have said it was neither easy nor difficult while the remaining felt it was easy as shown in Table 2. 
Table 2: Adapting to online sessions

\begin{tabular}{ll|r|r|r} 
& & & & \multicolumn{2}{c}{$\begin{array}{c}\text { Cumulative } \\
\text { Percent }\end{array}$} \\
\hline Extremely difficult & Frequency & Percent & Valid Percent & 1.5 \\
\hline Extremely easy & 1 & 1.5 & 38.8 & 40.3 \\
\hline Neither easy not difficult & 26 & 38.8 & 20.9 & 61.2 \\
\hline Somewhat difficult & 14 & 20.9 & 7.5 & 68.7 \\
\hline Somewhat easy & 5 & 7.5 & 31.3 & 100.0 \\
\hline Total & 21 & 31.3 & 100.0 & \\
\hline
\end{tabular}

$32.8 \%$ (22) of the participants felt that face to face sessions were better than online sessions, 37.3\% (25) said that face to face and online sessions offer similar benefit and $19.4 \%$ (13) felt that online sessions were better. $46.3 \%$ (31) preferred recorded sessions while $37.3 \%$ (25) preferred live sessions. The remaining 11 (16.4\%) participants preferred voiceover PowerPoint presentations.

52 participants agreed that online sessions were engaging, 50 participants said online sessions were conducive to seeking clarifications and 57 participants commented that accessing study material online was easy and 92.5\% (62) of participants found online tutorials helpful. 23.9\% (16) of the participants did not feel that the online sessions prepared them for assessments, so also 17 participants i.e., about $25.4 \%$ of the participants felt they were not able to seek clarifications in online sessions as shown in Table 3.

Table 3: Viewpoints on online sessions

\begin{tabular}{l|c|c|c|c|c}
\multirow{2}{*}{} & \multicolumn{1}{|c}{$\begin{array}{c}\text { Definitely } \\
\text { not }\end{array}$} & \multicolumn{1}{c}{$\begin{array}{c}\text { Probably } \\
\text { not }\end{array}$} & $\begin{array}{c}\text { Definitely } \\
\text { yes }\end{array}$ & $\begin{array}{c}\text { Probably } \\
\text { not }\end{array}$ & \multicolumn{2}{c}{$\begin{array}{c}\text { Probably } \\
\text { yes }\end{array}$} \\
\cline { 2 - 6 } Level of engagement & $4(6 \%)$ & $11(16.4 \%)$ & $19(28.4 \%)$ & $11(16.4 \%)$ & $33(49.3 \%)$ \\
\hline Seeking clarifications & $1(1.5 \%)$ & $16(23.9 \%)$ & $28(41.8 \%)$ & $16(23.9 \%)$ & $22(32.8 \%)$ \\
\hline $\begin{array}{l}\text { Accessing study } \\
\text { material }\end{array}$ & $1(1.5 \%)$ & $8(11.9 \%)$ & $29(43.3 \%)$ & $8(11.9 \%)$ & $28(41.8 \%)$ \\
\hline Online tutorials & $1(1.5 \%)$ & $4(6 \%)$ & $35(52.2 \%)$ & $4(6 \%)$ & $27(40.3 \%)$ \\
\hline $\begin{array}{l}\text { Preparation for } \\
\text { assessments }\end{array}$ & $4(6 \%)$ & $12(17.9 \%)$ & $24(35.8 \%)$ & $12(17.9 \%)$ & $27(40.3 \%)$ \\
\hline
\end{tabular}

To the question on transition into practical sessions following online sessions, $5(7.5 \%)$ of participants have reported it as being extremely difficult and $22(32.8 \%)$ have reported it as being difficult. $23(34.4 \%)$ students have reported it as being easy as shown in Table 4.

Table 4: Transition into practical sessions

\begin{tabular}{l|r|r|r|r} 
& & & \multicolumn{2}{c}{$\begin{array}{c}\text { Cumulative } \\
\text { Percent }\end{array}$} \\
\hline Extremely difficult & Frequency & Percent & Valid Percent & 7.5 \\
\hline Extremely easy & 5 & 7.5 & 7.5 & 14.9 \\
\hline Neither easy not difficult & 5 & 7.5 & 7.5 & 40.3 \\
\hline Somewhat difficult & 17 & 25.4 & 25.4 & 73.1 \\
\hline Somewhat easy & 22 & 32.8 & 32.8 & 100.0 \\
\hline Total & 18 & 26.9 & 26.9 & \\
\hline
\end{tabular}

Most participants (65.7\%) have reported COVID 19 as having a moderate impact on their academic life. 8 (11.9\%) participants reported being minimally affected by COVID 19 and 14 (20.9\%) of participants have reported a major impact due to COVID 19 as shown in table 5. 
Table 5: Impact of COVID 19 on academic life

\begin{tabular}{l|r|r|r|r} 
& Frequency & Percent & Valid Percent & \multicolumn{2}{c}{ Cumulative } \\
Percent
\end{tabular}

While age, ethnicity, year of enrolment, care-giving responsibilities, and employment status were not statistically significantly correlated to the impact of COVID 19 on academic life; adaptation to online sessions, the level of engagement, the ability to seek clarifications, preparation for assessments and the ease of transition into practical sessions were all positively correlated. The correlation was statistically significant. (Table 6)

Table 6: Bivariate Analysis

\begin{tabular}{l|c|r} 
& \multicolumn{2}{c}{$\begin{array}{c}\text { Impact of COVID 19 on academic life } \\
\text { Pearson } \\
\text { Correlation }\end{array}$} \\
\hline Adaptation to Online sessions & $0.334^{* *}$ & 0.006 \\
\hline Level of Engagement in Online sessions & $0.383^{* *}$ & 0.001 \\
\hline Seeking Clarifications in Online sessions & $0.357^{* *}$ & 0.003 \\
\hline Preparation for Assessments & $0.374 * *$ & 0.002 \\
\hline Transition into Practical sessions & $0.347^{* *}$ & 0.004 \\
\hline
\end{tabular}

Correlation is significant at the 0.05 level (2-tailed)

The open-ended questions section of the survey had 13 comments. Three themes emerged from the analysis.

\section{Relationships}

One comment from a participant enrolled in Year I commented on not being able to build relationships,

For a first year it meant you were not able to build bonds with your fellow peers.

\section{Learning}

The two comments made by two different participants on learning with online sessions were contradictory:

I cannot fully gain the knowledge via online study.

Online sessions amazing.

One participant commented on the challenge with transitioning into clinics:

The most impact was lack of clinic learning running alongside the lectures to supplement the lectures.

\section{Flexibility}

One participant commented on feeling safe while being in the safety of home.

Good flexibility and no risk of COVID

Two participants commented on care-giving responsibilities impacting online sessions very differently:

School child at home. Managing online education for child and myself at the same time was difficult.

I really prefer online I have a kid to manage. 


\section{DISCUSSION}

The survey had relatively low participation, potentially because of the timing. The survey link was sent to students at the end of the academic year. The low participation levels are comparable to similar studies in Malaysia, Bulgaria, and Algeria $(6,7,8)$. The final year students' participation was the least, likely to be due to the feeling of having completed the course.

When lockdowns were imposed, online teaching and learning methods were resorted to. Three approaches were used: live sessions through the university's online platform, recorded sessions posted on the online platform and voiceover PowerPoint presentations. The preference was for live sessions and recorded videos. This could be due to the connectivity that live sessions have with everyone doing the same thing at the same time. The recorded videos also have a sense of being dynamic and not monotonous. The voiceover PowerPoint presentations may have been less preferred because of the monotony. This finding is similar to the study on the perceptions of Indian medical students (9).

The finding of the acceptance of online sessions with the majority feeling that online sessions were either as good or better than face to face sessions is similar to the results obtained in a study of students from Dutch universities (10) and Bulgarian university (7). Our findings are in contrast with findings on university students in Algeria (8) and Malaysia (6). A study on dental students in Iran also reported low acceptability of online sessions and the reason attributed to low acceptance is not having computer skills (11). So also, the study on Indian dental students revealed poor acceptability due to lack of computers and technical issues (12).

Technical issues like accessibility and skills have been identified as one of the four barriers to online learning (13). Most of our students found adapting to technology easy and very few students reported having difficulties with internet access. Turchynova et al have emphasized that accessibility is a key issue in acceptance of online education. So also support for carrying out online activities is necessary for acceptability of online courses. The results of our study indicate that most of the students were satisfied with the support they received from the university (14).

Our finding of students feeling engaged in online sessions contrast with a study on students enrolled in a private university in Malaysia (6), were students reported difficulty focussing due to poor internet access. Very few students in our study cited disruption to access due to internet issues and felt supported by the learning management system.

Though most participants reported that online sessions were engaging, and the platform was conducive to seeking clarifications and accessing study material, a quarter felt the online sessions did not help with preparation for assessment.

A significant number of students felt the transition to practical sessions was difficult. This is because online instructions on the background and procedure is less likely to meet the requirements to develop competence in psychomotor skills. Our findings of the challenges faced by students when they returned to campus for practical sessions highlights the contextual role of the environment in teaching and learning (15). Clinical and preclinical education require students to be summoned to appropriate environments with suitable equipment and online sessions offer minimal support in achieving that (16).

The fear of getting COVID -19 in face-to-face settings may have also added to difficulties with transitioning into practical sessions. The study on Italian dental students revealed that face to face sessions like clinical training made students anxious and fearful (17). These negative emotions affect student wellbeing and their ability to engage in learning activities (18).

Overall, the participants felt that the pandemic had a moderate impact on their academic life. Though New Zealand had relatively lower number of cases and fewer and lesser lockdown periods, the students were concerned about the completion of the requirements to progress or graduate for a time in the academic year. This finding is similar to the finding of the study on Italian dental students who experienced "little to moderate worry" about the impact of the pandemic on their study career (17).

\section{CONCLUSION}

The pandemic has offered an opportunity for students and teachers alike to embrace innovative pedagogical approaches using technology that is conducive to active learning but has had a moderate impact on students' academic lives. The adaptability to and acceptability of online teaching and learning sessions has been high. A significant number of participants have reported finding the transitioning into practical sessions challenging. Our future strategies should anticipate these challenges and include approaches to make this transition easier.

\section{REFERENCES}

1. OECD (2020), Lessons for Education from COVID-19: A Policy Maker's Handbook for More Resilient Systems, OECD Publishing, Paris, Available from: https://doi-org.ezproxy.aut.ac.nz/10.1787/0a530888-en. 
2. Wanless S, Winterman E, Chapman J. Skills teaching in COVID lockdown in the UK: lessons learnt. Pielęgniarstwo XXI Wieku. 2020;19(3):171-173.

3. Norina F. COVID 19 challenges in dental health care and dental schools. Romanian Jo of Oral Rehabil. 2020;12(2):6-12.

4. Farooq I, Ali S, Moheet IA, AlHumaid J. COVID-19 outbreak, disruption of dental education, and the role of teledentistry. Pak J Med Sci. 2020;36(7):1726-1731.

5. Rizun M, Strzelecki A. Students' acceptance of the covid-19 impact on shifting higher education to distance learning in Poland. Int J Environ Res and Public Health. 2020;17(18):1-19.

6. Lau SL, Sim TY. Feedback of University Students on Online Delivery Learning During the COVID-19 Pandemic Period. IEEE; 2020; 13-21.

7. Angelova, M. (2020). Students' attitudes to the online university course of management in the context of COVID19. Int J Technol Educ Sci (IJTES), 4(4), 283-292.

8. Blizak D, Blizak S, Bouchenak O, Yahiaoui K. Students' Perceptions Regarding the Abrupt Transition to Online Learning during the COVID-19 Pandemic: Case of Faculty of Chemistry and Hydrocarbons at the University of Boumerdes--Algeria. J Chem Educ. 2020;97(9):2466-2471.

9. Agarwal S, Kaushik JS. Student's Perception of Online Learning during COVID Pandemic. Indian J Pediatr. 2020;87(7):554. DOI: 10.1007/s12098-020-03327-7

10. Suleri J. Learners' experience and expectations during and post COVID-19 in higher education. Res Hosp Manag. 2020;10(2):91-96.

11. Al-Taweel FB, Abdulkareem AA, Gul SS, Alshami ML. Evaluation of technology-based learning by dental students during the pandemic outbreak of coronavirus disease 2019. Euro J Dent Educ. 2021;25(1):183-190.

12. Shrivastava KJ, Nahar R, Parlani S, Murthy VJ. A cross-sectional virtual survey to evaluate the outcome of online dental education system among undergraduate dental students across India amid COVID-19 pandemic. Euro $J$ Dent Educ. Feb 2021. DOI: 10.1111/eje.12679

13. Surahman E, Sulthoni. Student Satisfaction toward Quality of Online Learning in Indonesian Higher Education During the Covid-19 Pandemic. IEEE; 2020. 120-125.

14. Yilmaz Ince E, Kabuk A, Diler I. Distance Education in Higher Education in the COVID-19 Oandemic Process: A case of Isparta Applied Sciences University. International J Technol Educ Sci. 2020, 4(4), 343-351.

15. Gamage KAA, Wijesuriya DI, Ekanayake SY, Rennie AEW, Lambert CG, Gunawardhana N. Online Delivery of Teaching and Laboratory Practices: Continuity of University Programmes during COVID-19 Pandemic. Educ Sci. 2020;10, 291-300.

16. Quinn B, Field J, Dixon J, Gorter R, Akota I, Manzanares MC, et al. COVID-19: The immediate response of european academic dental institutions and future implications for dental education. Euro J Dent Educ. 2020;24(4):811-814.

17. Generali L, Iani C, Macaluso GM, Montebugnoli L, Siciliani G, Consolo U. The perceived impact of the COVID19 pandemic on dental undergraduate students in the Italian region of Emilia-Romagna. Euro J Dent Educ. 2020, 13p. DOI: $10.1111 /$ eje. 12640

18. Mohammad N, Norah A, Dalal A. Mental health and well-being during the COVID-19 pandemic in higher education: Evidence from G20 countries. J Public Health Res. 2021;9(s1). 